\title{
Spatial Variability in Seasonal Prediction Skill of SSTs: Inherent Predictability or Forecast Errors?
}

\author{
ARUN KUMAR \\ Climate Prediction Center, NOAA/NWS/NCEP, College Park, Maryland \\ JIESHUN ZHU \\ Climate Prediction Center, NOAA/NWS/NCEP, and Earth System Science Interdisciplinary Center, \\ University of Maryland, College Park, College Park, Maryland
}

(Manuscript received 26 April 2017, in final form 21 October 2017)

\begin{abstract}
Seasonal prediction skill of SSTs from coupled models has considerable spatial variations. In the tropics, SST prediction skill in the tropical Pacific clearly exceeds prediction skill over the Atlantic and Indian Oceans. Such skill variations can be due to spatial variations in observing system used for forecast initializations or systematic errors in the seasonal prediction systems, or they could be a consequence of inherent properties of the coupled ocean-atmosphere system leaving a fingerprint on the spatial structure of SST predictability. Out of various alternatives, the spatial variability in SST prediction skill is argued to be a consequence of inherent characteristics of climate system. This inference is supported based on the following analyses. SST prediction skill is higher over the regions where coupled air-sea interactions (or Bjerknes feedback) are inferred to be stronger. Coupled air-sea interactions, and the longer time scales associated with them, imprint longer memory and thereby support higher SST prediction skill. The spatial variability of SST prediction skill is also consistent with differences in the ocean-atmosphere interaction regimes that distinguish between whether ocean drives the atmosphere or atmosphere drives the ocean. Regions of high SST prediction skill generally coincide with regions where ocean forces the atmosphere. Such regimes correspond to regions where oceanic variability is on longer time scales compared to regions where atmosphere forces the ocean. Such regional differences in the spatial characteristics of ocean-atmosphere interactions, in turn, also govern the spatial variations in SST skill, making spatial variations in skill an intrinsic property of the climate system and not an artifact of the observing system or model biases.
\end{abstract}

\section{Introduction}

Sea surface temperatures (SSTs) are an important factor influencing climate variations over the globe. SST variability in the tropical Pacific associated with El Niño-Southern Oscillation (ENSO) influences weather and climate worldwide. Since the first dynamical predictions of SSTs associated with ENSO variability three decades ago (Cane et al. 1986), the ability of dynamical models to predict ENSO has improved significantly, and ENSO SSTs are now successfully predicted several seasons ahead (e.g., Ji et al. 1994; Zhang et al. 2003; Chen et al. 2004; Jin et al. 2008; Kirtman and Min 2009; Zhu et al. 2012a; Xue et al. 2013). In addition, dynamical seasonal predictions based on coupled models also predict SSTs in other ocean basins, and skill in predicting

Corresponding author: Dr. Jieshun Zhu, jieshun.zhu@noaa.gov those SSTs, such as in the tropical Indian Ocean (e.g., Luo et al. 2007; Zhu et al. 2015) and tropical Atlantic Ocean (e.g., Hu and Huang 2007) and the extratropical oceans, including the North Atlantic (e.g., Hu et al. 2013), the North Pacific (e.g., $\mathrm{Hu}$ et al. 2014), and the southern subtropical Pacific (e.g., Guan et al. 2014), has also been documented.

Across different ocean basins, however, seasonal prediction systems demonstrate considerably different skill in the prediction of SSTs. Over the tropics, prediction skill of SSTs is clearly higher in the equatorial Pacific than in the Atlantic and Indian Oceans (Fig. 1). The underlying reasons of the spatial variability in SST skill are yet to be well understood: Is the regional contrast in prediction skill an intrinsic property of the climate system, or an artifact of the present state of the observing and prediction systems? It is possible that the lower skill in the tropical Atlantic and Indian Oceans is a 


\section{SST Predictive Skill in CFSv2L_nudg (1982-2010): Correlation}

(a) at 0-month lead

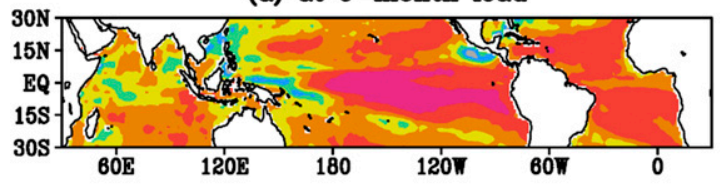

(c) at 2-month lead (b) at 1-month lead

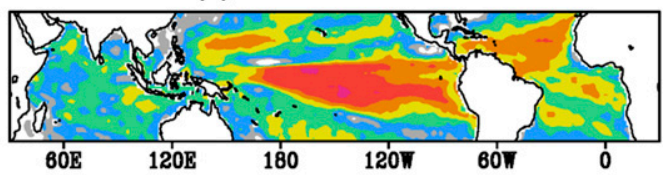

(d) at 3-month load

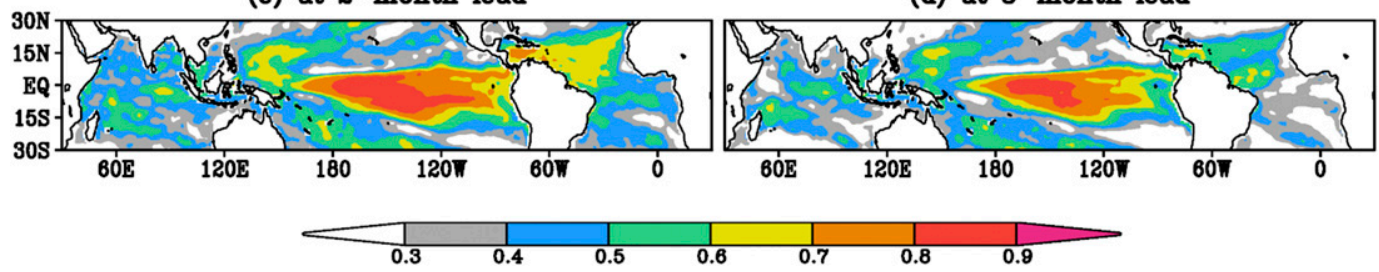

FIG. 1. Distribution of anomaly correlations between observed and predicted SST anomalies by HCST_CFSv2L_ nudg at lead times of (a) 0, (b) 1, (c) 2, and (d) 3 months. The hindcasts start from January, April, July, and October initial conditions during 1982-2010.

consequence of larger forecast errors due to 1) lack of observations needed to adequately initialize the state of the ocean or 2) model biases that could either influence the ingest of observational data or influence the utility of the assimilated observational data early during the forecast (e.g., resulting from initial shocks).

In this study, we also investigate another possibility for the spatial variability in SST prediction skill. We propose that the spatial variability in skill represents an inherent property of the climate system. The reasons for the spatial variability in skill are imbedded in the regional variations of 1) coupled ocean-atmosphere interactions and 2) regimes of ocean-atmosphere interactions. Regional characteristics in these two properties of the ocean-atmosphere system then also govern the inherent predictability of SSTs and impart their signature as regional variations in the prediction skill. The rest of the paper is arranged as follows. The model, experimental design, and datasets are described in the next section. Section 3 presents our analyses. A summary and discussion are given in section 4 .

\section{Model, experiments, and datasets}

The model (referred to as CFSv2L) used in this study is a variant of the NCEP CFSv2 (Saha et al. 2014) with lower horizontal resolutions in both atmospheric and oceanic components. In CFSv2L, the ocean model is the GFDL MOM version 4, which is configured for the global ocean with a horizontal grid of $1^{\circ} \times 1^{\circ}$ poleward of $30^{\circ} \mathrm{S}$ and $30^{\circ} \mathrm{N}$ and meridional resolution increasing gradually to $0.33^{\circ}$ between $10^{\circ} \mathrm{S}$ and $10^{\circ} \mathrm{N}$. The vertical coordinate is geopotential height $z$ with 40 levels (27 of them in the upper $400 \mathrm{~m}$ ), with maximum depth of approximately $4.5 \mathrm{~km}$. The atmospheric model of CFSv2L is the Global Forecast System, which has horizontal resolution at spectral T62 truncation, and 64 vertical levels in a hybrid sigma-pressure coordinate. The oceanic and atmospheric components of CFSv2L exchange surface momentum, heat, and freshwater fluxes, as well as SSTs, every $60 \mathrm{~min}$.

The spatial variability in SST skill is documented with the hindcast experiments described in Zhu et al. (2017). In the hindcasts, CFSv2L is initialized by a simple scheme in which SST is the only observed information applied to derive ocean initial states and no subsurface ocean observations are used. Specifically, six CFSv2L nudging integrations, differing by their initial conditions, were conducted with model forecast SSTs nudged to the observational counterpart. At the start of integrations, six initial conditions differ in ocean only, and are taken from the CFSR (Saha et al. 2010) ocean states at 0000 UTC 30 and 31 December 1980 and 1-3 January 1981, whereas the atmospheric and land initial conditions all use their CFSR states at 0000 UTC 1 January 1981. By redating all the initial conditions to 1 January 1976, six CFSv2L runs are integrated forward with model predicted SSTs nudged to the observed daily SSTs. The restoring time scale is chosen as 3.3 days, following our previous work with CFSv1 (Wang et al. 2013; Kumar et al. 2014). The observed daily SSTs are interpolated from the monthly National Oceanic and Atmospheric Administration (NOAA) Optimum Interpolation SST (OISST) version 2 (Reynolds et al. 2002) SSTs for the period after 1982, and from the ERSST.v3 (Smith et al. 2008) before 1982. The SST-nudged CFSv2L integrations are referred to as CFSv2L_nudg.

From the restart files saved during CFSv2L_nudg, hindcasts are next conducted starting from the first day of each January, April, July, and October during 1982-2010 
and last for eight months. The set of hindcasts is referred to as HCST_CFSv2L_nudg. The difference between CFSv2L_nudg and HCST_CFSv2L_nudg is that, whereas in the former observed SSTs are used throughout the integrations, for the latter the observed SST information is not used beyond the initial time.

The predicted SSTs are validated against the analyzed (observed) SSTs from OISSTv2 (Reynolds et al. 2002) and document the spatial variability in skill in predicting SSTs. Other monthly datasets used for diagnostics include precipitation data from NOAA's Climate Prediction Center (CPC) Merged Analysis of Precipitation (CMAP) (Xie and Arkin 1997), 10-m zonal winds from the CFSR (Saha et al. 2010), and the subsurface ocean fields from the NCEP Global Ocean Data Assimilation System (GODAS; Behringer 2007). All diagnostics are conducted over 1982-2011.

\section{Results}

Figure 1 presents the horizontal distributions of prediction skill of monthly mean SSTs in the tropics in HCST CFSv2L_nudg for the lead times from 0 to 3 months. As expected, the prediction skill over the whole tropics decreases as the lead time increases. Specifically, while the correlation skill is above 0.7 over most regions at 0 -month lead (Fig. 1a), it drops to below 0.7 over all regions except the central and eastern Pacific at 3-month lead (Fig. 1d). Of particular interest to us is the considerable spatial variability in the SST prediction skill, with higher skill in the tropical Pacific than in the other two tropical ocean basins. The spatial contrast in SST skill is present as early as at 0 -month lead and becomes increasingly pronounced at longer leads. While at 0-month lead prediction skill is approximately 0.9 in the central and eastern Pacific and approximately 0.8 in the tropical Indian and Atlantic Ocean basins (Fig. 1a), it is $0.7-0.8$ versus about 0.5 at 3 -month lead (Fig. 1d). We note that the contrast in prediction skill is not due to differences in the subsurface ocean observing systems among ocean basins as no subsurface ocean observations were used for inferring initial ocean states.

The spatial variability of SST prediction skill is a common feature in other forecast systems, including those using the sophisticated initialization scheme assimilating subsurface ocean observations (e.g., Xue et al. 2013; Chen et al. 2015). Previous studies usually attributed the low skill, for example, in the tropical Atlantic, to large model biases (e.g., Huang et al. 2007) and significant uncertainties in the ocean initializations (e.g., Zhu et al. 2012b). Alternatively, it is also possible that the spatial variability in skill is an inherent property of the climate system. In the following analysis, we demonstrate that it is indeed so.
We first demonstrate that regions with larger SST prediction skill tend to coincide with regions where the dynamical air-sea coupling (or Bjerknes feedback) is also stronger. To delineate the regions where the dynamical air-sea coupling is strong, we rely on the analysis of simulations in which model-simulated SSTs are nudged to observations during their integration (e.g., Wang et al. 2013; Kumar et al. 2014).

Over the regions with strong air-sea coupling, the inclusion of observed SST information results in a realistic simulation of surface winds, which in turn also generates the observed evolution in subsurface ocean temperature (or thermocline variability; Kumar et al. 2014). ENSO is one such phenomenon with a strong dynamical coupling, which is well substantiated by the success of the Cane-Zebiak model (Zebiak and Cane 1987) that encapsulates various aspects of the fundamental dynamics of coupled air-sea interactions. The SST forced simulations, therefore, allow us to infer regions with strong air-sea coupling either from a comparison of the simulated surface wind and subsurface ocean variability or based on a comparison of some measure of coupling with their observational counterpart.

A common way to demonstrate ocean-atmospheric coupling is to regress interannual variability in SST with surface wind. In the case of variability associated with ENSO this can be done based on regression of the monthly mean Niño-3.4 SST index with the monthly mean surface winds. This regression for observations and SST nudged simulation is compared in Fig. 2. We recall that in the SST nudged simulation the only observed information is SSTs, and the variability in surface winds is generated internally by model simulations. The spatial structure of the regression between monthly mean variability in the Niño-3.4 SST and $10-\mathrm{m}$ winds in observations (Fig. 2a) has a close resemblance with that in the model simulations (Fig. 2b). In the equatorial tropical Pacific associated with positive Niño-3.4 SST anomalies are easterly surface winds near and west of the date line. This feature is a consequence of above normal Niño-3.4 SST that leads to positive precipitation anomalies and low-level convergence. There are also similarities in regression patterns over other ocean basins: a wave train-like structure in northern and southern oceans and westerly winds anomalies over the eastern Indian Ocean. These patterns are part of a global response of the atmosphere to ENSO (e.g., Trenberth et al. 1998).

To further demonstrate the time coherency in surface winds simulated from the specification of SSTs via ocean-atmosphere coupled interactions in the model versus those in observations, time-longitude sections of the monthly mean surface winds along the equator in 
Regression of U10m vs. Nino34 (a) CFSR

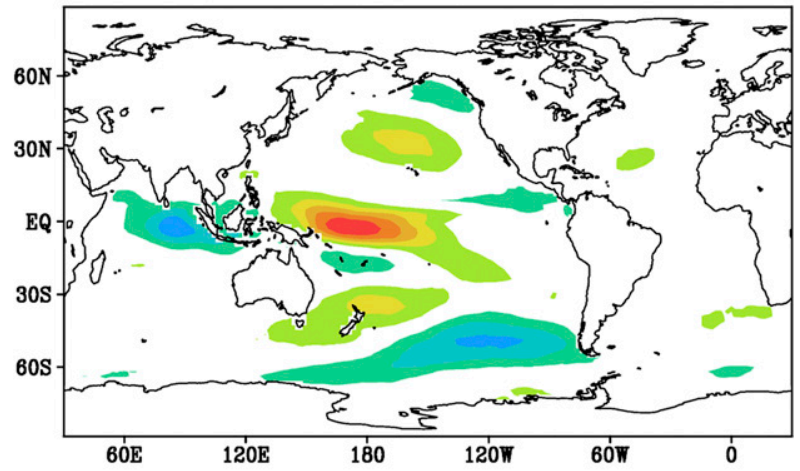

(b) CFSv2L_nudg

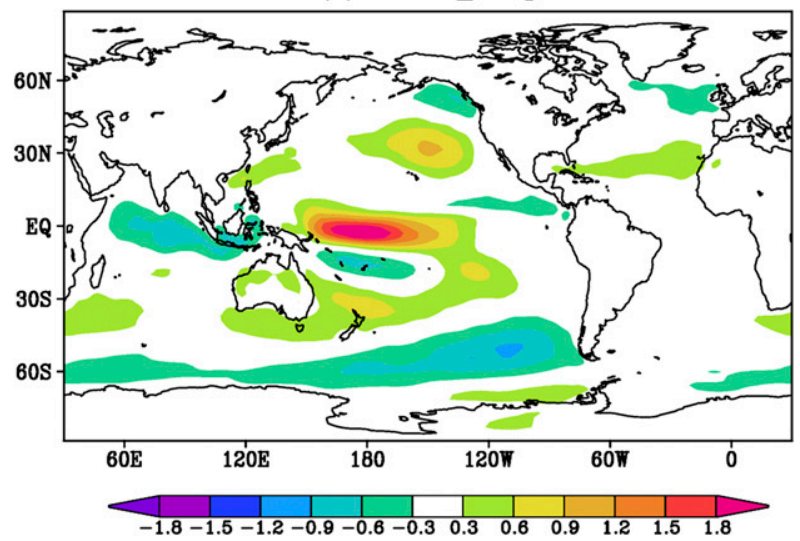

FIG. 2. Regression coefficient of $10-\mathrm{m}$ zonal wind vs Niño-3.4 SST index $\left(\mathrm{m} \mathrm{s}^{-1}{ }^{\circ} \mathrm{C}^{-1}\right)$ in (a) observations (CFSR winds and OISST) and (b) CFSv2L_nudg. Correlation is calculated regardless of season during 1982-2010.

observations and model simulations are shown in Fig. 3. This analysis does not restrict itself to the coupled air-sea interactions associated with Niño-3.4 SSTs alone. The analysis indicates that over certain oceanic regions along the equator, there is a good correspondence in observed and model simulated surface winds. Such regions include the equatorial tropical Pacific and eastern Indian Ocean, delineating the regions over which interannual variability is strongly influenced by coupled oceanatmosphere interactions.

The surface winds resulting from the specification of SSTs also generate the subsurface ocean variability. This is verified from the analysis of time-longitude comparison of simulated and observed depth of the $20^{\circ} \mathrm{C}$ isotherm (D20) at the equator (Fig. 4). In the equatorial tropical Pacific, the temporal evolution of the observed D20 anomalies associated with ENSO is well replicated in the model simulations with SST nudging. As the interannual variability in D20 in other ocean basins is not as strong as in the equatorial tropical Pacific, the correspondence between subsurface ocean evolution between observations and model simulations is better discerned from the analysis of the heat content variability in the upper $300 \mathrm{~m}$ of the ocean (HCA).

By showing the simulation skill of HCA in the SSTnudging simulation, the strength of ocean-atmosphere coupling in the tropics is further compared (Fig. 5). It is seen that the highest simulation skill is present in the tropical Pacific with correlations above 0.6 within the equatorial waveguide, a region that corresponds to the strongest dynamical air-sea coupling associated with ENSO. We note that the high simulation skill for HCA is not an artifact of specification of SSTs, and that strong air-sea coupling is a necessary condition to communicate the influence of SSTs to deeper ocean via the generation of required surface winds (Kumar et al. 2017).

In the tropical Indian Ocean, the simulation skill of HCA is smaller than that in the tropical Pacific, featured by relatively high correlations $(>0.4)$ in the tropical southwestern Indian Ocean, and in the eastern basins with a nearly symmetrical structure about the equator. These spatial distributions are reminiscent of the spatial structure of HCA associated with the leading mode of interannual variability of coupled ocean and atmospheric system in the tropical Indian Ocean (Fig. 1 of Huang and Kinter 2002). In the tropical Atlantic, the simulation skill of HCA is the smallest, and the relatively high correlations $(\sim 0.3)$ appear within the equatorial waveguide as well, and correspond to the dynamical air-sea coupling associated with the Atlantic Niño (Xie and Carton 2004).

From the analyses of the coupled model simulations where SSTs are nudged to the observed evolution, regions of strong ocean-atmosphere coupling can thus be discerned. The point to note is that the regions with strong ocean-atmosphere coupling also tend to coincide with regions where skill of SST prediction is also high. Overall, the distribution of the HCA simulation skill (i.e., the strength of ocean-atmosphere coupling) is consistent with the SST prediction skill, which is highest in the tropical Pacific and in the eastern Indian Ocean. SST prediction skill is lower in the Atlantic (with the exception in the northern tropical Atlantic, reasons for which will be discussed latter) and other regions of the Indian Ocean.

An alternate way to understand the spatial variations in SST prediction skill is to compare its spatial distribution with regime difference in ocean-atmosphere interactions, delineating when ocean drives the overlying atmosphere or atmosphere drives the underlying ocean. The spatial distribution of such regimes can be differentiated from the analysis of simultaneous correlation between SST and precipitation (SST-P; Kumar et al. 2013; Wu and 


\section{0-m Zonal Wind Anomaly $(\mathrm{m} / \mathrm{s})$}

(a) CFSR

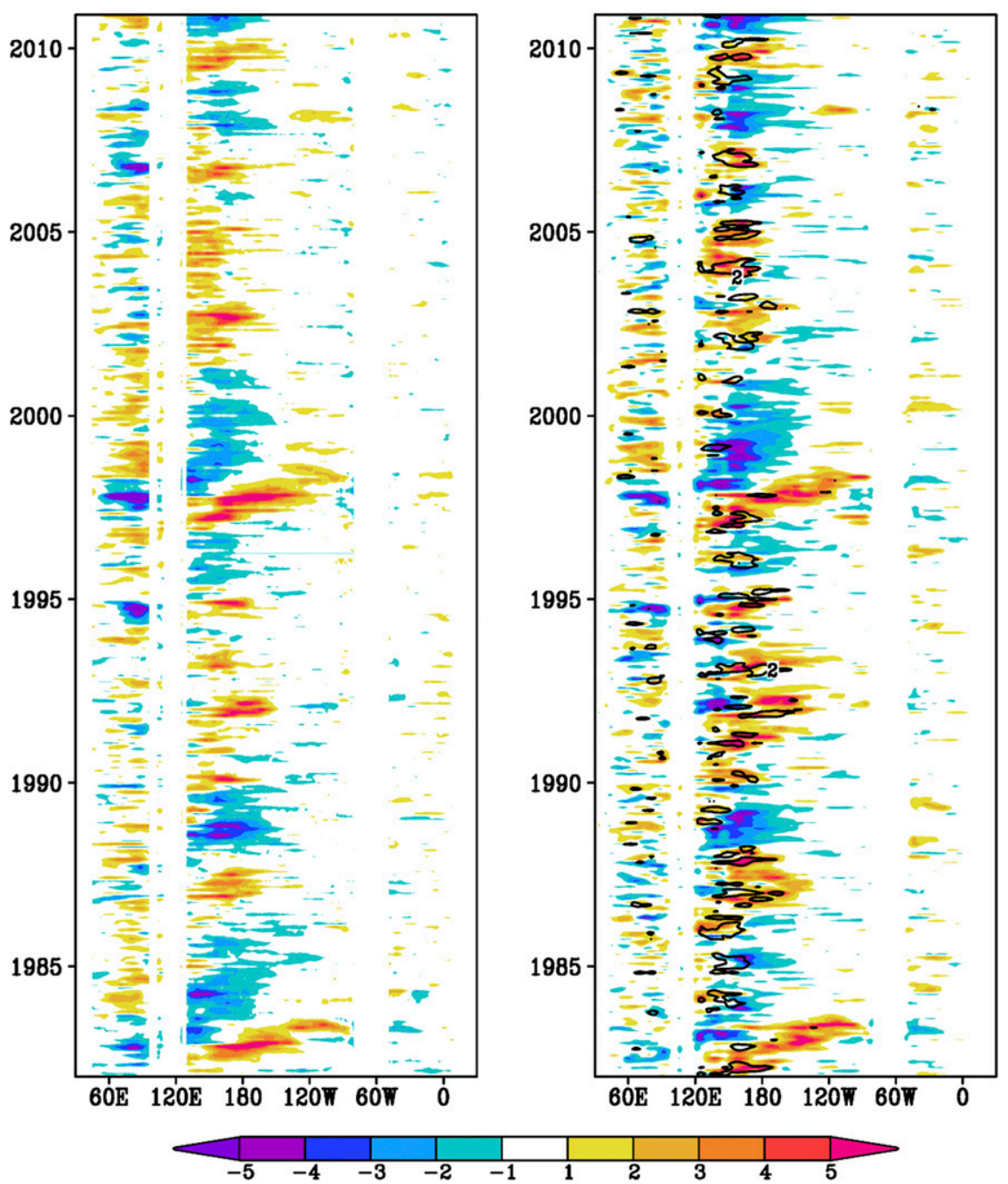

FIG. 3. The 10-m zonal wind anomaly at the equator $\left(\mathrm{m} \mathrm{s}^{-1}\right)$ in (a) observations (CFSR) and (b) CFSv2L_nudg (ensemble mean). In (b), the black contours (contour interval is $2 \mathrm{~m} \mathrm{~s}^{-1}$ ) represent the ensemble spread of six CFSv2L_nudg integrations.

Kirtman 2007). Over the regions where ocean drives the atmosphere (regime I), the correlation between interannual variability of SST and precipitation tends to be a large positive. This is because warmer (cooler) SST anomalies generate more (less) convective precipitation, which results in a positive SST- $P$ correlation. Further, because of longer time scales associated with oceanic variability, positive correlations are also sustained over a longer period.

In contrast, over the regions where atmosphere drives the ocean (regime II), larger precipitation is associated with more clouds and with less shortwave radiation reaching the ocean surface, and further, with stronger surface winds over the ocean resulting in stronger latent heat release from the ocean. Both processes cool the SST. Over such regions, negative SST $-P$ correlation occurs. Because the atmospheric variability is on a faster time scale, negative correlations are not sustained over a long period (and therefore have a smaller fingerprint on monthly mean variability) and tend to have smaller values. A more detailed discussion about such regimes can be found in Kumar et al. (2013).

Figure 6 presents the spatial distribution of SST $-P$ correlation in the tropics. It is seen that relatively strong positive SST $-P$ correlations occur in the equatorial oceans, and weak or even negative SST $-P$ correlations occur in the off-equatorial oceans. Also, among the three tropical oceans, the SST $-P$ correlations in the 


\section{Thermocline Anomaly (m)}

(a) GODAS

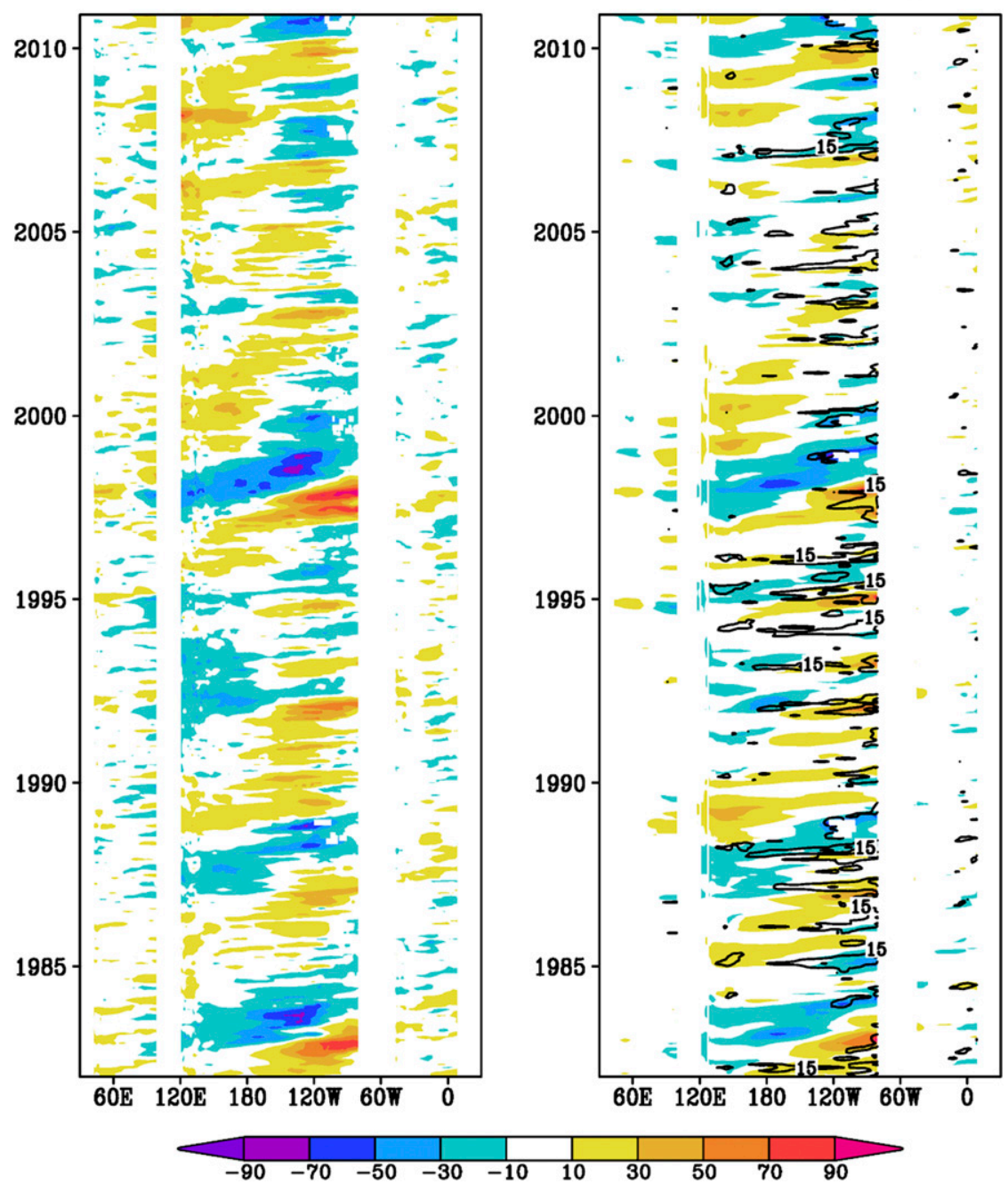

FIG. 4. Thermocline anomaly at the equator (m) in (a) observations (GODAS) and (b) CFSv2L_nudg (ensemble mean). The depth of the thermocline is derived based on D20. In (b), the black contours (contour interval is $15 \mathrm{~m}$ ) represent the ensemble spread of six CFSv2L_ nudg integrations.

equatorial Pacific are the highest. The spatial variability in the SST $-P$ correlation generally agrees with the SST skill distribution in Fig. 1. Overall, the SST prediction skill is generally high (low) over the regions where ocean forces the atmosphere (atmosphere forces the ocean).

The regions where coupled ocean-atmosphere coupling is prominent and the regions where local SST $-P$ correlation is a large positive are not independent. There is a physical linkage between the two. Coupled ocean-atmosphere interactions provide the following causal link: SST anomalies force the precipitation, which in turn forces the low-level winds. Low-level winds, by influencing subsurface temperature anomalies along the thermocline, then sustain (or reinforce) the SST anomalies, and thereby provide a long-time-scale memory. This chain of physical events responsible for coupled air-sea interaction, therefore, supports large positive SST $-P$ correlations as well. The CaneZebiak model (Zebiak and Cane 1987) encapsulates the key elements of coupling process among SST, precipitation, surface winds, and subsurface ocean memory (or thermocline variability) and has been successful in providing skillful SST predictions despite its simplicity.

It is also noted that there are few exceptions that cannot be explained by the above processes. For 


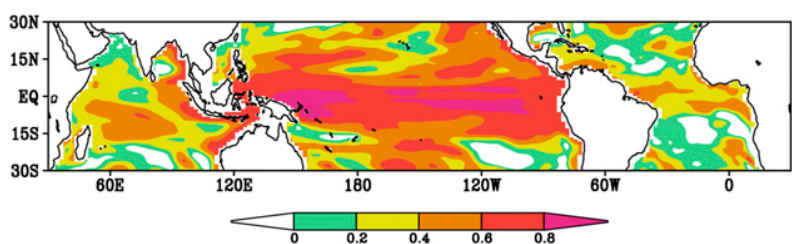

FIG. 5. Distribution of anomaly correlations between the GODAS-analyzed upper-ocean 300-m heat content anomalies and those derived by CFSv2L_nudg. Correlation is calculated regardless of season during 1982-2010.

example, in the northern tropical Atlantic, SST prediction skill is moderately high (Fig. 1), but the local dynamical coupling is relatively weak (Fig. 3). Previous studies (e.g., Hu and Huang 2007) have suggested that the prediction skill in this region is related to the remote forcing of ENSO. A large portion of SST variability over this region can be explained by the thermodynamical forcing of atmosphere, which is linked with ENSO (e.g., Huang et al. 2002). This remote forcing process is different from the reddening of stochastic atmospheric forcing (Frankignoul and Hasselmann 1977) and has long-lead predictability because of ENSO. Furthermore, the thermodynamical process means a decoupling between the mixed layer SST and the thermocline fluctuations in the region, which also explains the low HCA simulation skill in the SST-nudging simulations (Fig. 6). Kumar et al. (2013) differentiated such regions as regime III of ocean-atmospheric interactions.

Regions with coupled ocean-atmosphere interactions, and regions where local SST and precipitation correlation is positive and large, are also regions that have longer time scales for SST variability. Regions where SST variability is determined by the atmospheric variability, on the other hand, are associated with variability on faster time scales.

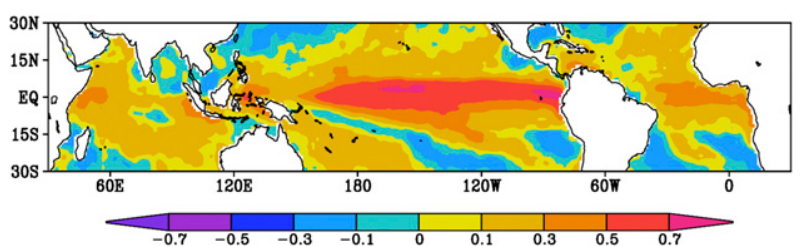

FIG. 6. Distribution of anomaly correlations between the SST and precipitation anomalies in observations. Correlation is calculated regardless of season during 1982-2010.

This spatial contrast in time scale of SST variability is reflected in the characteristic persistence time scale of SSTs.

Persistence can be defined in terms of autocorrelation. Because of the large thermal inertia of the ocean, SST anomalies generally have high persistence (Fig. 7). However, spatial inhomogeneity in persistence is also evident, with the SST anomalies being more persistent in the tropical Pacific than in the tropical Indian and Atlantic Oceans. Also, the SST anomalies in the northern tropical Atlantic have fairly high persistence. The spatial distribution of autocorrelation resembles well the spatial patterns of high correlation in HCA, and with the regions of large positive local correlation in SST and precipitation. For longer lead times, the autocorrelation drops; however, its spatial contrast remains. The spatial contrast in persistence is reflected well in the spatial variability in the skill of SST predictions, and it further supports the reasoning that the spatial variability in skill is due to the contrast in the characteristics of oceanatmosphere interactions over different oceanic regions.

\section{Conclusions and discussion}

Dynamical seasonal predictions, no matter whether they apply simple ocean initialization schemes (e.g., Luo et al. 2005; Zhu et al. 2017) or a sophisticated

SST Skill of Persistence (1982-2010): Correlation

(a) at 1-month lead

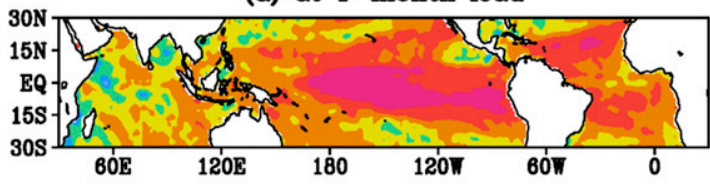

(c) at 3-month lead

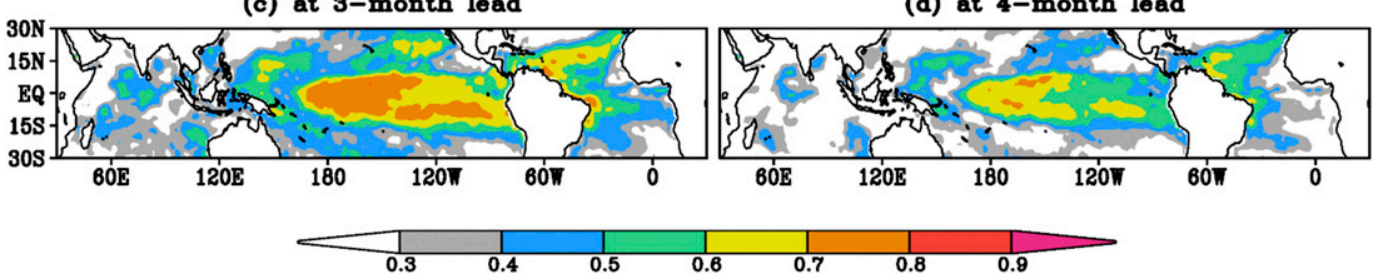

FIG. 7. As in Fig. 1, but for persistence predicted SSTA at lead times of (a) 1, (b) 2, (c) 3, and (d) 4 months. (b) at 2-month lead

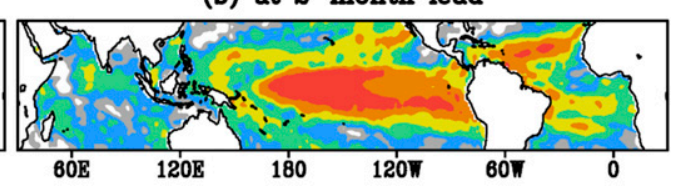

(d) at 4-month lead 
initialization schemes with the assimilation of subsurface ocean observations (e.g., Xue et al. 2013; Chen et al. 2015), have considerable spatial differences in skill in the prediction of SSTs. Over the tropics, for example, models clearly have higher SST prediction skill in the equatorial Pacific Ocean than in the Atlantic and Indian Oceans. One explanation for the spatial variability in skill could be that it reflects larger forecast errors in the tropical Atlantic and Indian Oceans due to either regional variations in the ocean observing system or large model biases that have regional characteristics.

In this paper, however, we argued that the spatial variability in SST skill is a manifestation of the inherent property of nature, specifically regional variations in the characteristics of ocean-atmosphere interactions. The spatial variability of prediction skill corresponds well with the regions where the dynamical air-sea coupling (or Bjerknes feedback) is stronger. Such regions were identified based on coupled simulations where forecast SSTs were nudged to observations. Furthermore, the spatial variability of SST prediction skill is also consistent with the regime difference based on whether ocean drives the atmosphere or atmosphere drives the ocean (and which can be differentiated based on local SST $-P$ correlations). In general, the SST prediction skill is high (low) over the regions where ocean forces the atmosphere (atmosphere forces the ocean). The analysis presented in the paper goes beyond merely linking the spatial variability in prediction skill of SSTs to the regions where either the SST persistence is high or SST variability on interannual time scales itself is high (not shown). We also provide a physical basis as to why spatial variations in persistence, or in the amplitude of SST variability, themselves exist. The physical basis relates to spatial variations in the strength of air-sea coupling or to regimes where ocean forces the atmosphere or vice versa (which themselves are also interconnected).

It should be noted that this study is not to argue that the limits of SST predictability have been achieved. In contrast, we believe that further improvements in SST predictions could be achieved through efforts put into improving the observing system, the initialization methods, and the coupled models. For example, an SST skill comparison between persistence (Fig. 7) and model (Fig. 1) shows that the region of high skill in the Pacific is meridionally wider in persistence than in model. Also, at lead times of 2 and 3 months (Figs. 1c,d and 7c,d), the skill of persistence in the northern tropical Atlantic is slightly higher than in model forecasts. In the far eastern Pacific off the South American coast, the model shows less skill than persistence. All these differences are indicative of model errors (initial conditions or models), indicating room for further improvement. However, because the spatial contrast in SST skill is an intrinsic property of the climate system, the spatial contrast in SST skill may prevail in spite of further improvements in skill.

Acknowledgments. We thank NOAA's Climate Program Office, Climate Observation Division for their support. JZ is partially supported by the NASA Ocean Salinity Science Team Grant NNX17AK09G.

\section{REFERENCES}

Behringer, D. W., 2007: The Global Ocean Data Assimilation System (GODAS) at NCEP. 11th Symp. on Integrated $\mathrm{Ob}$ serving and Assimilation Systems for the Atmosphere, Oceans, and Land Surface (IOAS-AOLS), San Antonio, TX, Amer. Meteor. Soc., 3.3, https://ams.confex.com/ams/87ANNUAL/ techprogram/paper_119541.htm.

Cane, M. A., S. E. Zebiak, and S. C. Dolan, 1986: Experimental forecast of El Niño. Nature, 321, 827-832, https://doi.org/10.1038/321827a0.

Chen, D., M. A. Cane, A. Kaplan, S. E. Zebiak, and D. J. Huang, 2004: Predictability of El Niño over the past 148 years. Nature, 428, 733-736, https://doi.org/10.1038/nature02439.

Chen, M., A. Kumar, and W. Wang, 2015: A study of the predictability of sea surface temperature over the tropics. Climate Dyn., 44, 1767-1776, https://doi.org/10.1007/s00382-014-2187-4.

Frankignoul, C., and K. Hasselmann, 1977: Stochastic climate models, Part II. Application to sea-surface temperature anomalies and thermocline variability. Tellus, 24, 289-305, https://doi.org/10.1111/j.2153-3490.1977.tb00740.x.

Guan, Y., J. Zhu, B. Huang, Z.-Z. Hu, and J. L. Kinter III, 2014: South Pacific Ocean dipole: A predictable mode on multiseasonal time scales. J. Climate, 27, 1648-1658, https://doi.org/ 10.1175/JCLI-D-13-00293.1.

Hu, Z.-Z., and B. Huang, 2007: The predictive skill and the most predictable pattern in the tropical Atlantic: The effect of ENSO. Mon. Wea. Rev., 135, 1786-1806, https://doi.org/ 10.1175/MWR3393.1.

— , A. Kumar, B. Huang, W. Wang, J. Zhu, and C. Wen, 2013: Prediction skill of monthly SST in the North Atlantic Ocean in NCEP Climate Forecast System version 2. Climate Dyn., 40, 2745-2759, https://doi.org/10.1007/s00382-012-1431-z.

,,,--- J. Zhu, and Y. Guan, 2014: Prediction skill of North Pacific variability in NCEP Climate Forecast System version 2: Impact of ENSO and beyond. J. Climate, 27, 42634272, https://doi.org/10.1175/JCLI-D-13-00633.1.

Huang, B., and J. L. Kinter III, 2002: The interannual variability in the tropical Indian Ocean. J. Geophys. Res., 107, 3199, https:// doi.org/10.1029/2001JC001278.

— , P. S. Schopf, and Z. Pan, 2002: The ENSO effect on the tropical Atlantic variability: A regionally coupled model study. Geophys. Res. Lett., 29, 2039, https://doi.org/10.1029/ 2002 GL014872.

— Z.Z.Z. Hu, and B. Jha, 2007: Evolution of model systematic errors in the tropical Atlantic basin from coupled climate hindcasts. Climate Dyn., 28, 661-682, https://doi.org/10.1007/ s00382-006-0223-8.

Ji, M., A. Kumar, and A. Leetmaa, 1994: A multiseason climate forecast system at the National Meteorological Center. Bull. Amer. Meteor. Soc., 75, 569-577, https://doi.org/10.1175/ 1520-0477(1994)075<0569:AMCFSA > 2.0.CO;2. 
Jin, E. K., and Coauthors, 2008: Current status of ENSO prediction skill in coupled ocean-atmosphere models. Climate Dyn., $\mathbf{3 1}$, 647-664, https://doi.org/10.1007/s00382-008-0397-3.

Kirtman, B. P., and D. Min, 2009: Multimodel ensemble ENSO prediction with CCSM and CFS. Mon. Wea. Rev., 137, 29082930, https://doi.org/10.1175/2009MWR2672.1.

Kumar, A., M. Chen, and W. Wang, 2013: Understanding prediction skill of seasonal mean precipitation over the tropics. J. Climate, 26, 5674-5681, https://doi.org/10.1175/JCLI-D-1200731.1 .

- , H. Wang, Y. Xue, and W. Wang, 2014: How much of monthly subsurface temperature variability in the equatorial Pacific can be recovered by the specification of sea surface temperatures? J. Climate, 27, 1559-1577, https://doi.org/10.1175/ JCLI-D-13-00258.1.

- C. Wen, Y. Xue, and H. Wang, 2017: Sensitivity of subsurface ocean temperature variability to specification of surface observations in the context of ENSO. Mon. Wea. Rev., 145, 14371446, https://doi.org/10.1175/MWR-D-16-0432.1.

Luo, J.-J., S. Masson, S. Behera, S. Shingu, and T. Yamagata, 2005: Seasonal climate predictability in a coupled OAGCM using a different approach for ensemble forecasts. J. Climate, 18, 4474-4497, https://doi.org/10.1175/JCLI3526.1.

,-- , S. K. Behera, and T. Yamagata, 2007: Experimental forecasts of the Indian Ocean dipole using a coupled OAGCM. J. Climate, 20, 2178-2190, https://doi.org/10.1175/ JCLI4132.1.

Reynolds, R. W., N. A. Rayner, T. M. Smith, D. C. Stokes, and W. Wang, 2002: An improved in situ and satellite SST analysis for climate. J. Climate, 15, 1609-1625, https://doi.org/10.1175/ 1520-0442(2002)015<1609:AIISAS > 2.0.CO;2.

Saha, S., and Coauthors, 2010: The NCEP Climate Forecast System Reanalysis. Bull. Amer. Meteor. Soc., 91, 1015-1058, https:// doi.org/10.1175/2010BAMS3001.1.

— , and Coauthors, 2014: The NCEP Climate Forecast System version 2. J. Climate, 27, 2185-2208, https://doi.org/10.1175/ JCLI-D-12-00823.1.

Smith, T. M., R. W. Reynolds, T. C. Peterson, and J. Lawrimore, 2008: Improvements to NOAA's historical merged landocean surface temperature analysis (1880-2006). J. Climate, 21, 2283-2296, https://doi.org/10.1175/2007JCLI2100.1.

Trenberth, K. E., G. W. Branstator, D. Karoly, A. Kumar, N.-C. Lau, and C. Ropelewski, 1998: Progress during TOGA in understanding and modeling global teleconnections associated with tropical sea surface temperatures. J. Geophys. Res., 103, 14 291-14 324, https://doi.org/10.1029/97JC01444.
Wang, H., A. Kumar, and W. Wang, 2013: Characteristics of subsurface ocean response to ENSO assessed from simulations with the NCEP Climate Forecast System. J. Climate, 26, 80658083, https://doi.org/10.1175/JCLI-D-12-00795.1.

$\mathrm{Wu}, \mathrm{R}$., and B. P. Kirtman, 2007: Regimes of seasonal air-sea interaction and implications for performance of forced simulations. Climate Dyn., 29, 393-410, https://doi.org/10.1007/ s00382-007-0246-9.

Xie, P. and P. A. Arkin, 1997: Global precipitation: A 17-year monthly analysis based on gauge observations, satellite estimates, and numerical model outputs. Bull. Amer. Meteor. Soc., 78, 2539-2558, https://doi.org/10.1175/1520-0477(1997)078<2539: GPAYMA $>2.0 . \mathrm{CO} ; 2$.

Xie, S.-P., and J. A. Carton, 2004: Tropical Atlantic variability: Patterns, mechanisms, and impacts. Earth's Climate: The Ocean-Atmosphere Interaction, Geophys. Monogr., Vol. 147, Amer. Geophys. Union, 121-142, https://doi.org/10.1029/ $147 \mathrm{GM} 07$.

Xue, Y., M. Chen, A. Kumar, Z.-Z. Hu, and W. Wang, 2013: Prediction skill and bias of tropical Pacific sea surface temperatures in the NCEP Climate Forecast System version 2. J. Climate, 26, 5358-5378, https://doi.org/10.1175/ JCLI-D-12-00600.1.

Zebiak, S. E., and M. A. Cane, 1987: A model of El Niño-Southern Oscillation. Mon. Wea. Rev., 115, 2262-2278, https://doi.org/ 10.1175/1520-0493(1987)115<2262:AMENO>2.0.CO;2.

Zhang, R.-H., S. E. Zebiak, R. Kleeman, and N. Keenlyside, 2003: A new intermediate coupled model for El Niño simulation and prediction. Geophys. Res. Lett., 30, 2012, https://doi.org/ 10.1029/2003GL018010.

Zhu, J., B. Huang, L. Marx, J. L. Kinter III, M. A. Balmaseda, R.-H. Zhang, and Z.-Z. Hu, 2012a: Ensemble ENSO hindcasts initialized from multiple ocean analyses. Geophys. Res. Lett., 39 , L09602, https://doi.org/10.1029/2012GL051503.

$\ldots, \ldots$, and M. Balmaseda, 2012b: An ensemble estimation of the variability of upper-ocean heat content over the tropical Atlantic Ocean with multi-ocean reanalysis products. Climate Dyn., 39, 1001-1020, https://doi.org/10.1007/ s00382-011-1189-8.

_, _ _ A. Kumar, and J. L. Kinter III, 2015: Seasonality in predictive skill and predictable patterns of tropical Indian Ocean SST. J. Climate, 28, 7962-7984, https://doi.org/10.1175/ JCLI-D-15-0067.1.

, A. Kumar, H.-C. Lee, and H. Wang, 2017: Seasonal predictions using a simple ocean initialization scheme. Climate Dyn., 49, 3989-4007, https://doi.org/10.1007/s00382-017-3556-6. 